\title{
Matching the Modules: Cortical Maps and Long- Range Intrinsic Connections in Visual Cortex during Development
}

\author{
Kerstin E. Schmidt, Ralf A. W. Galuske, Wolf Singer \\ Max-Planck Institut für Hirnforschung, Abteilung Neurophysiologie, Deutschordenstraße 46, \\ 60528 Frankfurt a. M., Germany
}

Received 10 May 1999; accepted 20 May 1999

\begin{abstract}
Visual cortical neurons exhibit a high degree of response selectivity and are grouped into small columns according to their response preferences. The columns are located at regularly spaced intervals covering the whole cortical representation of the visual field with a modular system of feature-selective neurons. The selectivity of these cells and their modular arrangement is thought to emerge from interactions in the network of specific intracortical and thalamocortical connections. Understanding the ontogenesis of this complex structure and contributions of intrinsic and extrinsic, experiencedependent mechanisms during cortical development can provide new insights into the way the visual cortex processes information about the environment. Available data about the development of connections and response
\end{abstract}

properties in the visual cortex suggest that maturation proceeds in two distinct steps. In the first phase, mechanisms inherent to the cortex establish a crude framework of interconnected neural modules which exhibit the basic but still immature traits of the adult state. Relevant mechanisms in this phase are assumed to consist of molecular cues and patterns of spontaneous neural activity in cortical and corticothalamic interconnections. In a second phase, the primordial layout becomes refined under the control of visual experience establishing a fine-tuned network of connections and mature response properties. ๑ 1999 John Wiley \& Sons, Inc. J Neurobiol 41: 10-17, 1999

Keywords: orientation preference; long-range intrinsic connections; development; map; visual cortex
The highly specialized response properties of cortical neurons result from the elaborated anatomical and functional architecture of the neocortex in which the neurons are embedded. Within the primary visual cortex neurons with similar response properties are grouped in columns or modules that extend vertically through the cortical lamination. Long-range intrinsic axons reciprocally link columns of similar functional properties that are spaced at regular intervals. Therefore, functional properties and the architecture of connections are closely related. The evidence that both functional properties and anatomical architecture mature under the influence of visual experience and are

Correspondence to: K. E. Schmidt

(C) 1999 John Wiley \& Sons, Inc. CCC 0022-3034/99/010010-08 modifiable by manipulating experience raises the question to which extent the layout of visual representations in functional maps is based on genetic and epigenetic factors, respectively. In the following, we review data on the development of feature maps and intracortical circuitry focusing on the development of orientation selectivity in the visual cortex of cats and ferrets.

\section{SPATIAL PROPERTIES OF ORIENTATION PREFERENCE MAPS IN PRIMARY VISUAL CORTEX}

The preferred orientation of neurons in the cortex changes continuously in a plane tangential to the cortical lamination and preferences for the same ori- 
entation repeat at rather regular intervals (Hubel and Wiesel, 1962). Metabolic mapping techniques such as 2-deoxyglucose autoradiography (Sokoloff et al., 1977) suggested a two-dimensional arrangement of iso-orientation columns in parallel slabs or irregular blobs (Hubel et al., 1977; Albus, 1979; Singer, 1981; Löwel and Singer, 1987; Humphrey et al., 1980). The more comprehensive mapping technique based on optical imaging of intrinsic signals (Grinvald et al., 1986) revealed subsequently that the different orientation domains are not perfectly parallel to each other, but are arranged radially around singularities, at which the preferred orientations change rapidly (Bonhoeffer and Grinvald, 1991).

There is evidence that orientation selectivity at least in the adult mainly originates from the specific and precise alignment of thalamocortical connections onto layer IV neurons (Chapman et al., 1991; Reid and Alonso, 1995; Ferster et al., 1996), as originally suggested by Hubel and Wiesel (1962).

In addition to orientation preference, neurons exhibit preferences for either the ipsi- or the contralateral eye and form bandlike alternating ocular dominance columns (Hubel and Wiesel, 1965, 1972; Shatz et al., 1977). Within these columns, the neurons in layer IV which receive the eye-specific input from the thalamus exhibit the strongest eye preference. In normally reared cats, most of the neurons in supra- and infragranular layers are binocular with only a bias for one eye (Hubel and Wiesel, 1962). Earlier 2-deoxyglucose studies failed to reveal a relation between the maps of ocular dominance and orientation preference (monkeys: Hubel et al., 1978; cats: Löwel et al., 1988). However, recent investigations with optical imaging revealed consistent relations between the two columnar systems in both monkeys and cats as originally suggested by Hubel and Wiesel (1977). Orientation singularities were found to be located predominantly within the centers or peaks of ocular dominance columns and the trajectories of iso-orientation domains cross the borders between adjacent ocular dominance columns significantly more often at right angles than expected from an even distribution (Bartfeld and Grinvald, 1992; Obermayer and Blasdel, 1993; Crair et al., 1997; Hübener et al., 1997; Löwel et al., 1998).

\section{INTRINSIC AND ENVIRONMENTAL INFLUENCES ON THE DEVELOPMENT OF ORIENTATION SELECTIVITY}

In kitten visual cortex, the earliest neuronal responses to light flashes applied through the still closed eyelids were recorded at the fourth postnatal day (PND4) (Huttenlocher, 1967). Orientation-selective responses were found to variable degrees as early as the eyes open around PND10 in cats (Hubel and Wiesel, 1963, Blakemore and Van Sluyters, 1975; Buisseret and Imbert, 1976; Albus and Wolf, 1984; Braastad and Heggelund, 1985; but see Barlow and Pettigrew, 1971; for a detailed review, see Fregnac and Imbert, 1984) and around PND23 in ferrets (Chapman and Stryker, 1993). A 2-deoxyglucose study provided evidence for a modular organization of orientation preference at PND21 in cats (Thompson et al., 1983), and recent optical imaging data demonstrated orientation preference maps in area 17 of cats as early as PND14 (Crair et al., 1998) and in area 17 of ferrets at PND33 (Chapman et al., 1996). Most studies agree that in cats the maturation of orientation selectivity occurs independently of visual experience within the first 3 weeks (Blakemore and VanSluyters, 1975; Buisseret and Imbert, 1976; Fregnac and Imbert, 1978; Mower et al., 1981). The quality of cortical maps improves over this period irrespective of whether kittens are normally reared or visually deprived (Goedecke et al., 1996; Crair et al., 1998).

This initial experience-independent formation of orientation maps is followed by a second developmental phase during which further maturation is influenced by visual experience. With normal vision, the overall proportion and responsiveness of orientation-selective neurons increase steadily until the sixth postnatal week in cats (for review, see Fregnac and Imbert, 1984) and the seventh postnatal week in ferrets (Chapman and Stryker, 1993). In cats, visual input is required beyond the third postnatal week for the maintenance and further elaboration of orientation-selective responses and the organization of neurons into iso-orientation domains. Deprivation from pattern vision in this second phase leads to a marked deterioration of the already established cellular response properties (for review, see Fregnac and Imbert, 1984; Henry et al., 1994) and orientation preference maps (Crair et al., 1998). However, the earliest maturing orientation-selective neurons which prefer vertical or horizontal contours, are located mainly in layer IV and driven through the contralateral eye (Blakemore and VanSluyters, 1975; Buisseret and Imbert, 1976; Fregnac and Imbert, 1978; Crair et al., 1998; ferrets: Chapman and Bonhoeffer, 1998), seem to resist visual deprivation (Leventhal and Hirsch, 1980; Buisseret et al., 1982; Thompson et al., 1983).

The development of functional properties can also be influenced by manipulating the nature of visual experience. The proportion of neurons displaying a certain orientation preference can be selectively in- 
creased by exposing animals to an environment containing only contours of this very orientation (Hirsch and Spinelli, 1971; Blakemore and VanSluyters, 1975; Leventhal and Hirsch, 1975; Blasdel et al., 1977; Stryker et al., 1978; Flood and Coleman, 1979; Rauschecker and Singer, 1981; Singer, 1981; Sengpiel et al., 1998; for review, see Fregnac and Imbert, 1984; Henry et al., 1994). These changes in the distribution of preferred orientations appear to be due to a shift toward the experienced orientation in neurons whose initial tuning already allowed them to respond to that orientation. Neurons which are initially unable to respond to the experienced orientation maintain their original preference. Since only those stimuli which match the receptive field properties of the postsynaptic neuron effectively induce modifications, postsynaptic activation is presumably required for these changes to occur (Cynader and Mitchell, 1977; Rauschecker and Singer; 1979; Singer et al., 1981).

\section{LONG-RANGE INTRINSIC CONNECTIONS}

In principle, two types of intrinsic connections can be distinguished in the visual cortex: local connections confined to columns or the close neighborhood, and long-range connections between neurons located in different columns. The latter type of connections forms a reciprocal system of axon collaterals which arborize at regular distances of about $1 \mathrm{~mm}$. Both physiological and anatomical evidence from several species indicates that this system preferentially links cortical columns with similar functional properties, e.g., the same orientation preference (Ts'o et al., 1986; Gilbert and Wiesel, 1989; Schwarz and Bolz, 1991; Hata et al., 1991; Malach et al., 1993, 1994; Bosking et al., 1997). Tangential connections between iso-orientation domains exhibit in addition an axial anisotropy, linking neurons with colinearly aligned receptive fields over longer distances than neurons preferring similar but not colinear orientations (Fitzpatrick, 1996; Schmidt et al., 1997a).

In the adult, long-range connections contribute to the generation of orientation and direction selectivity (Eysel et al., 1987, 1990), mediate the dynamic modulation of receptive field properties by stimuli presented outside the classical receptive field (for review, see Gilbert, 1998), and contribute to the synchronization of responses (for review, see Singer and Gray, 1995).

\section{DEVELOPMENT OF LONG-RANGE INTRINSIC CONNECTIONS}

In cat and ferret visual cortex, long-range intrinsic connections develop only postnatally, and they do so in two phases: First, a network of crudely clustered long-range connections forms between pyramidal neurons located mainly in supragranular layers. Subsequently, these crude clusters become refined and the total length of the reciprocal connections increases by $50-100 \%$. This process of refinement and extension of tangential intrinsic connections appears to take 4-6 weeks in the cat (Luhmann et al., 1990; Callaway and Katz, 1990; Galuske and Singer, 1996) and 3 weeks in the ferret (Ruthazer and Stryker, 1996; Durack and Katz, 1996).

The initial clustering of tangential connections is likely to be independent of visual experience: First, crude clusters in both kittens and ferrets emerge before eye opening, around PND10 in cats (Luhmann et al., 1986; Callaway and Katz, 1990; Galuske and Singer, 1996) and around PND27 in ferrets (Durack and Katz, 1996; Ruthazer et al., 1996). Second, clustered intrinsic connections are present in animals binocularly deprived from birth (Luhmann et al., 1990; Callaway and Katz, 1991). Third, dark rearing (Luhmann et al., 1990) or blocking retinal activity (Ruthazer and Stryker, 1996) does not prevent the initial clustering, either. The only manipulation so far which prevents the clustering of tangential connections is the blockade of neuronal activity within the cortex (Ruthazer and Stryker, 1996). This suggests that the early patterning of these connections is achieved by intrinsic processes whereby self-generated activity in cortical or reciprocal corticothalamic circuits might play an important role.

Morphological studies indicate that the earliest long-range intrinsic connections do not originate from neurons in the cortical plate, the progenitor of the prospective cortical layers II-VI, but from cells in cortical layer I and the subplate (Galuske and Singer, 1996). These cells are among the first to be generated and to reach their target position, but most of them are transient and disappear again (Luskin and Shatz, 1985). The neurons in the subplate, a cortical compartment below layer VI, have been shown to be decisive for cortical development. They gate and guide the ingrowth of thalamic afferents (Ghosh and Shatz, 1994), constituting the first target for LGN afferents and projecting back to the thalamus (for review, see Shatz et al., 1990). In analogy, the connections among these early transient cells in the subplate and in layer I could serve as a scaffold for the 
subsequent development of tangential connections originating from the later maturing pyramidal cells, e.g., by generating periodically modulated activity patterns.

The second phase of the development of longrange intrinsic connections is influenced by pattern vision. Both the refinement of the connections that transforms the crudely clustered network into the highly selective mature state (Luhmann et al., 1990, Callaway and Katz, 1991; but see Lübke and Albus, 1992) and the elongation of connections up to $8 \mathrm{~mm}$ (Luhmann et al., 1990) are prevented by binocular visual deprivation. The refinement of the connections is mainly based on the elimination of axon collaterals to possibly inappropriate locations (Callaway and Katz, 1991). It is an interesting unresolved question whether these eliminated axons had already contacted target cells before elimination, and if so, whether they became inappropriate owing to maturation-related alterations in the functional properties of the interacting cells. One reason for such alterations could be cortical growth: The surface of the primary visual cortex increases by at least $40 \%$ between the third and sixth postnatal week in cats (Duffy et al., 1998; Rathjen et al., 1998). This enlargement is thought to be based on the elaboration of dendritic and axonal elements and the addition of myelin, neurogenesis, and neuronal migration having come to an end by that time (Luskin and Shatz, 1985). However, despite this enlargement of the cortical surface, the periodicity of interconnected modules does not change significantly between the end of the second postnatal week and adulthood (Galuske and Singer, 1996; Rathjen et al., 1998). This implies that the number of modules connected by clustered intrinsic connections increases. Since no new cells are formed, division of existing clusters appears to be the most likely scenario. Irrespective of the mechanism for the generation of new clusters, it seems inevitable that clusters shift their location to keep their spacing constant during cortical growth. This, in turn, could be associated with a change in the neuron's orientation preference and necessitate rearrangement of some of the already established tangential connections.

\section{RELATION BETWEEN CORTICAL MAPS AND LONG-RANGE INTRINSIC CONNECTIONS DURING DEVELOPMENT}

Although not studied longitudinally in the same animal, data from cat and ferret visual cortex suggest that the early clustering of intrinsic connections (Callaway and Katz, 1990; Luhmann et al., 1990, Galuske and Singer, 1996, Ruthazer and Stryker, 1996, Durack and Katz, 1996) precedes the formation of orientation preference maps by a few days (Crair et al., 1998; Chapman et al., 1996). However, a small proportion of orientation selective neurons has been observed around or slightly before the time of the initial clustering of tangential connections in the cat (Hubel and Wiesel, 1965; Blakemore and VanSluyters, 1975) and ferret (Chapman and Stryker, 1993). There is thus a close temporal correlation between the clustering of tangential connections and the appearance of orientation-selective responses.

Both early orientation selectivity and initial clustering of connections are likely to be shaped by intracortical interactions. Self-generated patterned waves of retinal activity (Meister et al., 1991) do not appear to be crucial (Chapman et al., 1993; Weliky and Katz, 1996; Ruthazer et al., 1996). Hence, the initial symmetry breaking in the network of horizontal connections could be due to intracortically generated activity patterns. Whether the response properties of the early maturing orientation selective neurons in layer IV are also generated by the influence of such activity patterns on the cortical circuitry is unknown. Alternatively, the response properties of these neurons could be predetermined by local interactions, e.g. anisotropic inhibition, and these in turn could influence the structure of spontaneous activity. Both scenarios would render cortical cells selective for particular input constellations, e.g., for input patterns generated by elongated contours once visual input is available. This initial reponse bias could then promote the selection of the appropriate array of thalamic input connections. Support for this hypothesis comes from several lines of evidence: First, in the course of reversed monocular deprivation cortical neurons become disconnected from the initially deprived eye (Antonini and Stryker, 1994), and upon reversal get reconnected to this eye. During reversal, cells pass through a phase in which they are unresponsive to stimulation of either eye, but upon reconnection to the newly opened eye they express the same orientation preferences as before (Mioche and Singer, 1989). Second, the orientation maps remain unchanged during reversal of monocular deprivation (Kim and Bonhoeffer, 1994; Antonini et al., 1998). Third, orientation maps are similar for the two eyes even if the two eyes never received common visual experience (Goedecke and Bonhoeffer, 1996). These results suggest that the orientation preference of cortical neurons is determined by intracortical interactions and that the selection of the specific alignment of thalamic afferents (Chapman et al., 1991) which supports the re- 


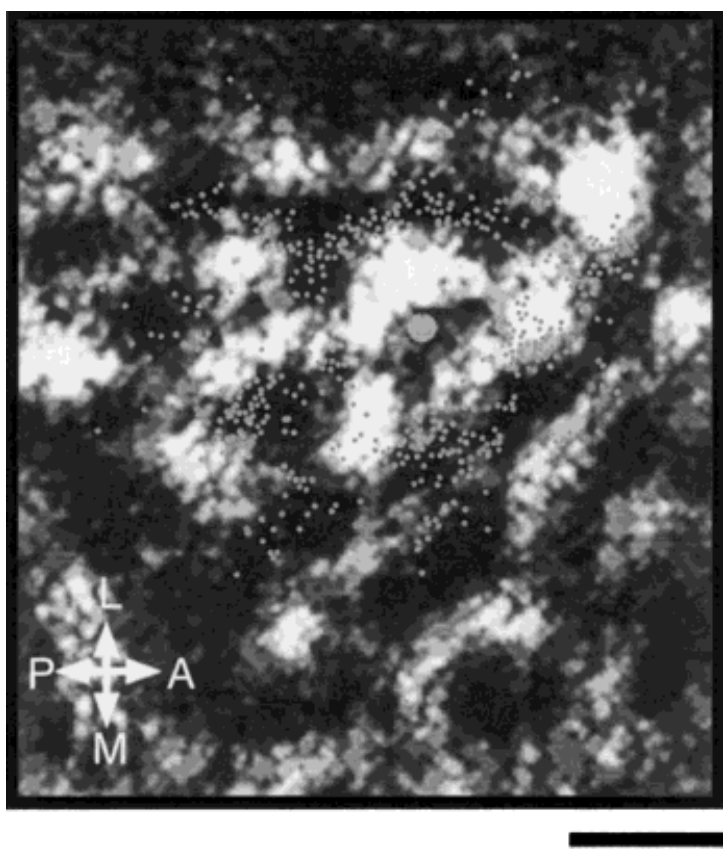

Figure 1 Topographic relations between intrinsic horizontal connections and monocular orientation domains (dark columns) in area 17 of a squinting cat (Schmidt et al., 1997b). A retrograde tracer (green fluorescent beads) was injected in a left eye orientation domain preferring $45^{\circ}$ (thick dot, light gray) and iso-orientation domains were labeled by 2-deoxyglucose during monocular stimulation of the left eye with moving oblique bars $\left(45^{\circ}\right)$. A detail of the autoradiograph from a flat-mount section of the unfolded left hemisphere was superimposed with the distribution of retrogradely labeled neurons (small dots, light gray) that have long-range connections to the injection site. Note the close correspondence of green-labeled neurons and darklabeled iso-orientation domains. Scale bar $=1 \mathrm{~mm}$. A $=$ anterior; $\mathrm{L}=$ lateral; $\mathrm{P}=$ posterior; $\mathrm{M}=$ medial.

spective preferences is achieved through an activitydependent process. As proposed previously (Rauschecker and Singer, 1981), a Hebbian mechanism evaluating the contingency of pre- and postsynaptic firing could ensure that selection of reconnecting thalamic afferents occurs according to the cortically determined orientation preferences of the respective target cells.

Even after eye opening, orientation tuning and the selectivity of intrinsic connections continue to improve independently of visual experience (Blakemore and VanSluyters, 1975; Buisseret and Imbert, 1976; Fregnac and Imbert, 1978; Crair et al., 1998; Callaway and Katz, 1991), suggesting continued prevalence of the intrinsic specification processes. Such a prolongation of experience-independent development beyond eye opening could serve to prevent substantial activity-dependent remodeling before the sensory pe- riphery and the motor control of the eyes have matured sufficiently.

In cats, visual experience influences the further maturation of orientation selectivity and the refinement of intrinsic connections beyond the beginning of the fourth postnatal week. At this stage, binocular deprivation affects both maps and connections, suggesting that visual experience serves to consolidate the already formed connections and to specify the still proliferating connections according to functional criteria. This process may also contribute to the reorganization of circuits associated with the implementation of new columns during cortical growth. If experience indeed serves to guide this reorganization process and to integrate newly formed connections into the already existing network, this could explain why the initially well-expressed maps deteriorate with long-term binocular deprivation.

Support for the hypothesis that the primordial orientation map is established by an experience-independent process and that the alignment of thalamic afferents is the result of a secondary, experiencedependent selection process comes from squinting animals. Because their visual axes are deviating, the input from the two eyes is permanently decorrelated, abolishing convergence onto common target cells and leading to a maximal segregation of thalamocortical afferents into ocular dominance territories (Shatz et al., 1977; Löwel and Singer, 1993). In this case, clustered tangential connections which normally connect neurons driven from either eye avoid interconnecting territories of different ocularity (Löwel and Singer, 1992). Despite this nearly complete eye-specific segregation of thalamic inputs and intracortical connections, iso-orientation domains were found to be continuous across territories of different ocularity (Löwel et al., 1998) as in normal animals (Hübener et al., 1997). Moreover, horizontal connections within the respective eye-specific subcompartments link isoorientation domains as selectively as in normal animals (Schmidt et al., 1997b). Taken together, these findings are consistent with the view that (a) the formation of the orientation map precedes the selection of thalamic input and is resistent to rearrangements of thalamic afferents, (b) the susceptibility of horizontal connections to experience-dependent selection persists beyond the phase during which the orientation map stabilizes, and (c) orientation selectivity, once established, is maintained by local, intracolumnar, and/or short-range intercolumnar interactions since sequence regularity of orientation preference is maintained across the domains of different ocularities that are no longer connected by long-range tangential fibers. 

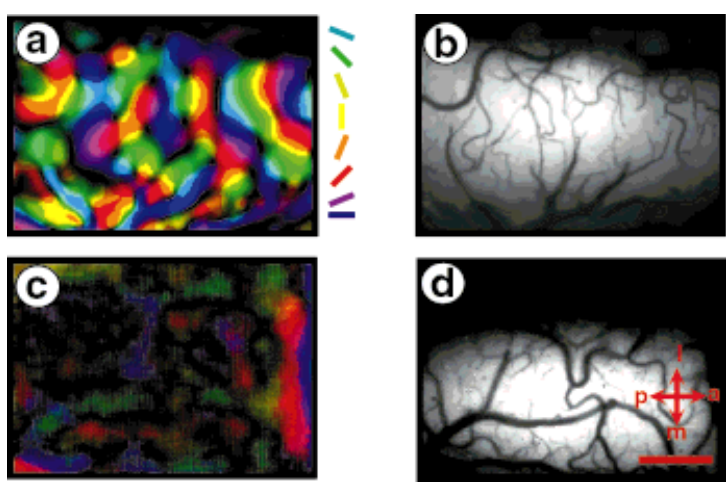

Figure 2 Influence of visual experience on the maturation of orientation maps (Galuske, unpublished observations). $(\mathrm{a}, \mathrm{c})$ Polar maps from optically recorded orientation maps in cat visual cortex. These maps result from vectorial summation of four different binocular single orientation maps $\left(0^{\circ}\right.$, $45^{\circ}, 90^{\circ}$, and $135^{\circ}$ ). The angle of the resulting vector is color coded according to the scheme shown on the right edge of (a). In addition, the orientation tuning is indicated by the brightness of the respective pixels; bright colors indicate a narrow tuning, and dark colors a broad tuning. Note the well-tuned orientation domains in the map recorded from a normally reared adult animal (a). In a binocularly deprived adult animal (c) the pixels are poorly tuned, as indicated by the preponderance of dark colors. Moreover, orientation domains are not well segregated and variable in size. Video images of the recorded regions are shown in the normal (b) and the deprived animal (d). Scale bar $=1 \mathrm{~mm}$. Abbreviations as in Figure 1.

In summary, the early development of the orientation map appears to be independent of retinal input and is likely to be based on intrinsic interactions that also support the clustering of tangential connections. This protonetwork could serve as a scaffold for the later, experience-dependent refinement of both thalamo-cortical and intracortical connections. The role of experience could be to make thalamic inputs congruent with the internally specified response properties of cortical neurons and to refine and validate intracortical connections according to functional criteria.

\section{REFERENCES}

Albus K. 1979. ${ }^{14}$ C-Deoxyglucose mapping of orientation subunits in the cat's visual cortical areas. Exp Brain Res 37:609-613.

Albus K, Wolf W. 1984. Early post-natal development of neuronal function in the kitten's visual cortex: a laminar analysis. J Physiol 348:153-185.

Antonini A, Gillespie DC, Crair MC, Stryker MP. 1998.
Morphology of single geniculocortical afferents and functional recovery of the visual cortex after reverse monocular deprivation. J Neurosci 18:9896-9909.

Antonini A, Stryker MP. 1994. Rapid remodeling of axonal arbors in the visual cortex. Science 260:1819-1821.

Barlow HB, Pettigrew JD. 1971. Lack of specificity of neurones in visual cortex of young kittens [Abstr]. J Physiol (Lond) 218:98-100.

Bartfeld E, Grinvald A. 1992. Relationship between orientation preference pinwheels, cytochrome oxidase blobs, and ocular dominance columns in primate striate cortex. Proc Natl Acad Sci USA 89:11905-11909.

Blakemore C, Van Sluyters RC. 1974. Reversal of the physiological effects of monocular deprivation in kittens: further evidence for a sensitive period. J Physiol (Lond) 237:195-216.

Blakemore C, Van Sluyters RC. 1975. Innate and environmental factors in the development of the kitten's visual cortex. J Physiol (Lond) 248:663-716.

Blasdel GG, Mitchell DE, Muir DW, Pettigrew JD. 1977. A physiological and behavioural study in cats of the effect of early visual experience with contours of a single orientation. J Physiol (Lond) 265:615-636.

Bonhoeffer T, Grinvald A. 1991. Iso-orientation domains in cat visual cortex are arranged in pinwheel-like patterns. Nature 353:429-431.

Bosking WH, Zhang Y, Schofield B, Fitzpatrick D. 1997. Orientation selectivity and the arrangement of horizontal connections in tree shrew striate cortex. J Neurosci 17: 2112-2127.

Braastad BO, Heggelund P. 1985. Development of spatial receptive field organization and orientation selectivity in kitten striate cortex. J Neurophysiol 53:1158-1178.

Buisseret P, Gary-Bobo E, Imbert M. 1982. Plasticity in the kitten's visual cortex: effects of the suppression of visual experience upon the orientational properties of visual cortical cells. Dev Brain Res 4:417-426.

Buisseret P, Imbert M. 1976. Visual cortical cells: their developmental properties in normal and dark reared kittens. J Physiol (Lond) 255:511-525.

Callaway EM, Katz LC. 1990. Emergence and refinement of clustered horizontal connections in cat striate cortex. J Neurosci 10:1134-1153.

Callaway EM, Katz LC. 1991. Effects of binocular deprivation on the development of clustered horizontal connections in cat striate cortex. Proc Natl Acad Sci USA 88:745-749.

Chapman B, Stryker MP. 1993. Development of orientation selectivity in ferret visual cortex and effects of deprivation. J Neurosci 13:5251-5262.

Chapman B, Stryker MP, Bonhoeffer T. 1996. Development of orientation preference maps in ferret primary visual cortex. J Neurosci 16:6443-6453.

Chapman B, Zahs KR, Stryker MP. 1991. Relation of cortical cell orientation selectivity to alignment of receptive fields of the geniculocortical afferents that arborize within a single orientation column in ferret visual cortex. J Neurosci 11:1347-1358. 
Crair MC, Gillespie DC, Stryker MP. 1998. The role of visual experience in the development of columns in cat visual cortex. Science 279:566-570.

Crair MC, Ruthazer ES, Gillespie DC, Stryker MP. 1997. Ocular dominance peaks at pinwheel center singularities of the orientation map in cat visula cortex. J Neurophysiol 77:3381-3385.

Cynader M, Mitchell DE. 1977. Monocular astigmtism effetcs on kitten visual cortex development. Nature 270: 177-178.

Duffy KR, Murphy KM, Jones DG. 1998. Analysis of the postnatal growth of visual cortex. Vis Neurosci 15:831839.

Durack JC, Katz LC. 1996. Development of horizontal projections in layer $2 / 3$ of ferret visual cortex. Cereb Cortex 6:178-183.

Eysel UT, Crook JM. 1990. GABA-induced remote inactivation reveals cross-orientation inhibition in the cat striate cortex. Exp Brain Res 80:626-630.

Eysel UT, Wörgötter F, Pape H-C. 1987. Local cortical lesions abolish lateral inhibition in the cat striate cortex. Exp Brain Res 68:606-612.

Ferster D, Chung S, Wheat H. 1996. Orientation selectivity of thalamic input to simple cells of cat visual cortex. Nature 380:249-252.

Fitzpatrick D. 1996. The functional organization of local circuits in visual cortex: insights from the study of tree shrew striate cortex. Cereb Cortex 6:329-341.

Flood DG, Coleman PD. 1979. Demonstration of orientation columns with $\left[\mathrm{C}^{14}\right]$-2-deoxyglucose in a cat reared in a striped environment. Brain Res 173:538-542.

Frégnac Y, Imbert M. 1978. Early development of visual cortical cells in normal and dark-reared kittens: relationship between orientation selectivity and ocular dominance. J Physiol (Lond) 278:27-44.

Frégnac Y, Imbert M. 1984. Development of neuronal selectivity in primary visual cortex of cat. Physiol Rev 64:325-434.

Galuske RAW, Singer W. 1996. The origin and topography of long-range intrinsic projections in cat visual cortex: a developmental study. Cereb Cortex 6:417-430.

Ghosh A, Shatz CJ. 1994. Segregation of geniculocortical afferents during the critical period: a role for subplate neurons. J Neurosci 14:3862-3880.

Gilbert CD. 1998. Adult cortical dynamics. Physiol Rev 78:467-485.

Gilbert CD, Wiesel TN. 1989. Columnar specificity of intrinsic horizontal and corticocortical connections in cat visual cortex. J Neurosci 9:2432-2442.

Gödecke I, Bonhoeffer T. 1996. Development of identical orientation maps for two eyes without common visual experience. Nature 379:251-254.

Gödecke I, Kim D-S, Bonhoeffer T, Singer W. 1997. Development of orientation preference maps in area 18 of kitten visual cortex. Eur J Neurosci 9:1754-1762.

Grinvald A, Lieke E, Frostig RD, Gilbert CD, Wiesel TN. 1986. Functional architecture of cortex revealed by optical imaging of intrinsic signals. Nature 324:361-364.
Hata Y, Tsumoto T, Sato H, Tamura H. 1991. Horizontal interactions between visual cortical neurons studied by cross-correlation analysis in the cat. J Physiol 441:593614.

Henry GH, Michalski A, Wimborne BM, McCart RJ. 1994. The nature and origin of orientation specificty in neurons of the visual pathways. Prog Neurobiol 43:381-437.

Hirsch HVB, Spinelli DN. 1971. Modification of the distribution of receptive field orientation in cats by selective exposure during devlopment. Exp Brain Res 13:509-527.

Hubel DH, Wiesel TN. 1962. Receptive fields, binocular interaction and functional architecture in the cat's visual cortex. J Physiol 160:106-154.

Hubel DH, Wiesel TN. 1963. Receptive fields of cells in striate cortex of very young, visually inexperienced kittens. J Neurophysiol 26:994-1002.

Hubel DH, Wiesel TN. 1965. Binocular interaction in striate cortex of kittens reared with artificial squint. J Neurophysiol (Lond) 206:419-436.

Hubel DH, Wiesel TN, Stryker MP. 1977. Orientation columns in macaque monkey visual cortex demonstrated by the 2-deoxyglucose autoradiographic technique. Nature 269:328-330.

Hubel DH, Wiesel TN, Stryker MP. 1978. Anatomical demonstration of orientation columns in macaque monkey. J Comp Neurol 177:361-380.

Hubel DH, Wiesel TN. 1972. Laminar and columnar distribution of geniculo-cortical fibers in the macaque monkey. J Comp Neurol 146:421-450.

Hübener M, Shoham D, Grinvald A, Bonhoeffer T. 1997. Spatial relationships among three columnar systems in cat area 17. J Neurosci 17:9270-9284.

Humphrey AL, Skeen LC, Norton TT. 1980. Topographic organization of the orientation column system in the striate cortex of the tree shrew (Tupaia glis).II. Deoxyglucose mapping. J Comp Neurol 192:549-566.

Huttenlocher PR. 1967. Development of cortical neuronal activity in the neonatal cat. Exp Neurol 17:247-262.

Kim D-S, Bonhoeffer T. 1994. Reverse occlusion leads to a precise restoration of orientation preference maps in visual cortex. Nature 370:370-372.

Leventhal AG, Hirsch HVB. 1975. Cortical effect of early selective exposure to diagonal lines. Science 190:902904.

Leventhal AG, Hirsch HVB. 1980. Receptive field properties of different classes of neurons in visual cortex of normal and dark reared cats. J Neurophysiol 43:11111132.

Löwel S, Singer W. 1992. Selection of intrinsic horizontal connections in the visual cortex by correlated neuronal activity. Science 255:209-212.

Löwel S, Singer W. 1993. Monocular induced 2-deoxyglucose patterns in the visual cortex and lateral geniculate nucleus of the cat: II. Awake animals and strabismic animals. Eur J Neurosci 5:857-869.

Löwel S, Freeman B, Singer W. 1987. Topographic organization of the orientation column system in large flat- 
mounts of the cat visual cortex: a 2-deoxyglucose study. J Comp Neurol 255:401-415.

Löwel S, Schmidt KE, Kim D-S, Wolf F, Hoffsümmer F, Singer W, Bonhoeffer T. 1998. The layout of orientation and ocular dominance domains in area 17 of strabismic cats. Eur J Neurosci 10:2629-2643.

Lübke J, Albus K. 1992. Rapid reaarangement of intrinsic tangential connections in the striate cortex of normal and dark reared kittens: lack of exuberance beyond the second postnatal week. J Comp Neurol 323:42-58.

Luhmann HJ, Martínez-Millán L, Singer W. 1986. Development of horizontal intrinsic connections in cat striate cortex. Exp Brain Res 63:443-448.

Luhmann HJ, Singer W, Martínez-Millán L. 1991. Horizontal interactions in cat striate cortex: I. Anatomical substrate and postnatal development. Eur J Neurosci 2:344357.

Luskin MB, Shatz CJ. 1985. Neurogenesis of the cat's primary visual cortex. J Comp Neurol 242:611-631.

Malach R, Amir Y, Harel M, Grinvald A. 1993. Relationship between intrinsic connections and functional architecture revealed by optical imaging and in vivo targeted biocytin injections in primate striate cortex. Proc Natl Acad Sci USA 90:10469-10473.

Malach R, Tootell RBH, Malonek D. 1994. Relationship between orientation domains, cytochrome oxidase stripes, and intrinsic horizontal connections in sqirrel monkey area V2. Cereb Cortex 4:151-165.

Meister M, Wong ROL, Baylor DA, Shatz CJ. 1991. Synchronous bursts of action potentials in ganglion cells of the developing mammalian retina. Science 252:939-943.

Mioche L, Singer W. 1989. Chronic recordings from single sites of kitten striate cortex during experience-dependent modifications of receptive-field properties. J Neurophysiol 62:185-197.

Mower GD, Berry D, Burchfiel JL, Duffy FH. 1981. Comparison of the effects of dark reaing and binocular suture on development and plasticity of cat visual cortex. Brain Res 220:255-276.

Obermayer K, Blasdel GG. 1993. Geometry of orientation and ocular dominance columns in monkey striate cortex. J Neurosci 13:4114-4129.

Rathjen S, Schmidt KE, Singer W, Löwel S. 1998. Postnatal growth of cat primary visual cortex revealed by early ocular dominance patterns. Soc Neurosci Abstr 24:895.

Rauschecker JP, Singer W. 1979. Changes in the circuitry of the kitten visual cortex are gated by postsynaptic activity. Nature 280:58-60.

Rauschecker JP, Singer W. 1981. The effects of early visual experience on the cat's visual cortex and their possible explanation by Hebb synapses. J Physiol 310:215-239.

Reid RC, Alonso JM. 1995. Specificity of monosynaptic connections from thalamus to visual cortex. Nature 378: 281-284.

Ruthazer ES, Stryker MP. 1996. The role of activity in the development of long-range connections in area 17 of the ferret. J Neurosci 16:7253-7269.
Schmidt KE, Goebel R, Löwel S, Singer W. 1997a. The perceptual grouping criterion of colinearity is reflected by anisotropies of connections in primary visual cortex. Eur J Neurosci 9:1083-1089.

Schmidt KE, Kim D-S, Singer W, Bonhoeffer T, Löwel S. 1997b. Functional specificity of long-range intrinsic and interhemispheric connections. J Neurosci 17:5480-5492.

Schwarz C, Bolz J. 1991. Functional specificity of a longrange connection in cat visual cortex: a cross-correlation study. J Neurosci 11:2995-3007.

Sengpiel F, Gödecke I, Stawinski P, Hübener M, Löwel S, Bonhoeffer T. 1998. Intrinsic and environmental factors in the development of functional maps in cat visual cortex. Neuropharmacology 37:607-621.

Shatz CJ, Ghosh A, McConnell SK, Allendoerfer KL, Friauf E, Antonini A. 1990. Pioneer neurons and target selection in cerebral cortical development. Cold Spring Harbor Symp Quant Biol 55:469-480.

Shatz CJ, Luskin MB. 1986. The relationship between the geniculocortical afferents and their cortical target cells during development of the cat's primary visual cortex. J Neurosci 6:3655-3668.

Shatz CJ, Lindstroem TN, Wiesel TN. 1977. The distribution of afferents representing the left and the right eyes in the cat's visual cortex. Brain Res 131:103-116.

Singer W. 1981. Topographic organization of orientation columns in the cat visual cortex: a deoxyglucose study. Exp Brain Res 44:431-426.

Singer W, Freeman B, Rauschecker J. 1981. Restriction of visual experience to a single orientation affects the organization of orientation columns in cat visual cortex. Exp Brain Res 41:199-215.

Singer W, Gray CM. 1995. Visual feature integration and temporal correlation hypothesis. Annu Rev Neurosci 18: $555-586$.

Sokoloff L, Reivich M, Kennedy C, DesRosiers MH, Patlak CS, Pettigrew KD, Sakurada O, Shinohara M. 1977. The $\left[{ }^{14} \mathrm{C}\right]$ deoxyglucose method for the measurement of local cerebral glucose utilization: theory, procedure, and normal values in the conscious and anesthetized albino rat. J Neurochem 28:897-916.

Stryker MP, Sherk H, Leventhal AG, Hirsch HVB. 1978. Physiological consequences for the cat's visual cortex of effectively resticting early visual experience with oriented contours. J Neurophysiol 41:896-909.

Thompson ID, Kossut M, Blakemore C. 1983. Development of orientation columns in cat striate cortex revealed by 2-deoxyglucose autoradiography. Nature 301:712-715.

Ts'o D, Gilbert CD, Wiesel TN. 1986. Relationships between horizontal interactions and functional architecture in cat striate cortex as revealed by cross-correlation analysis. J Neurosci 6:1160-1170.

Weliky M, Katz LC. 1996. Disruption of orientation tuning in visual cortex by artificially correlated neuronal activity. Nature 386:680-685. 